Research Notes

\title{
Effects of Renewable Energies and Big Data on the Biggest Spanish Energy Power Companies' Business Models
}

\author{
Pablo de Mergelina
}

Organizational Engineering, Business Administration and Statistics, Universidad Politécnica de Madrid, Madrid, Spain

\author{
Article history \\ Received: 07-03-2020 \\ Revised: 20-04-2020 \\ Accepted: 08-05-2020 \\ Email: p.demergelina@alumnos.upm.es
}

\begin{abstract}
Since the emergence of renewable energy sources and thanks to the encouragement of governments and the interest of citizens in an economical, environmentally friendly and sustainable system, the electricity sector is in a transition to renewable energy. Renewable energy is not simply the cornerstone of a transaction, but an entire electric revolution. Literature review reveals the following question: How will their business models evolve accordingly? Interviews were conducted with innovation managers of the biggest power companies in Spain to shed some light on the effects of two innovation sources on business models: Renewables energies and big data. Research revealed that renewable energy represents a complete paradigm shift. Until now, the system's net energy balance is achieved by adjusting the power generation to the demand for it. However, in a renewable system the generation cannot be controlled and, then, it is the energy consumption that must be adjusted to the generation. Renewable energy and big data involve the replacement of traditional generation resources with the resource of information, increasingly necessary to predict the generation and consumption of electricity.
\end{abstract}

Keywords: Business Model, Power, Renewable Energies, Big Data, Spain, Innovation

\section{Introduction}

Development of technology, industrial advancements, new methodologies and other discoveries respond to exponential evolution worldwide, including the electric power sector. Triggers for the electric revolution have been the search for energy independence, the depletion of traditional resources and the concern for the environment. While the political engine is crucial for the development of renewable energies, it is not the only factor. In fact, countries that promote and drive different factors have a more successful pace of development, becoming a fundamental part for the development of each technology to generate a set of appropriate drivers (Darmani et al., 2014). Winston (2014) states that "we can't build a prosperous future without the resources and innovation that business provides". Companies are the change leaders forward a more efficient and sustainable society model. It is within companies, particularly their business models, where the real power of change for the future electric power industry lies.

Besides, it should be borne in mind that more development can be achieved by innovating the different parts of the business than by innovating energy sources.
Moreover, "its business model innovation may achieve what technological and product innovation have long failed to deliver" (Girotra and Netessine, 2011). The end of this electric revolution will be achieved mainly thanks to new technologies and innovation, new models of energy supply management and new models on demand management. In other words, the renewable energy revolution will be achieved through business models innovation. But how are these sources of innovation affecting power company models actually? The objective of the present research is to identify the effects of renewable energies and big data on the business models of the biggest energy power companies in Spain.

\section{Theoretical Framework}

\section{What is a Business Model?}

In one of its simplest definitions, "business models are stories that explain how an enterprise works" (Magretta, 2002). A business model is the set of main activities, key decisions and hypotheses that, dependent on each other, theoretically determine the functioning of a company and its behavior in the environment, becoming an essential instrument to manage the company. 


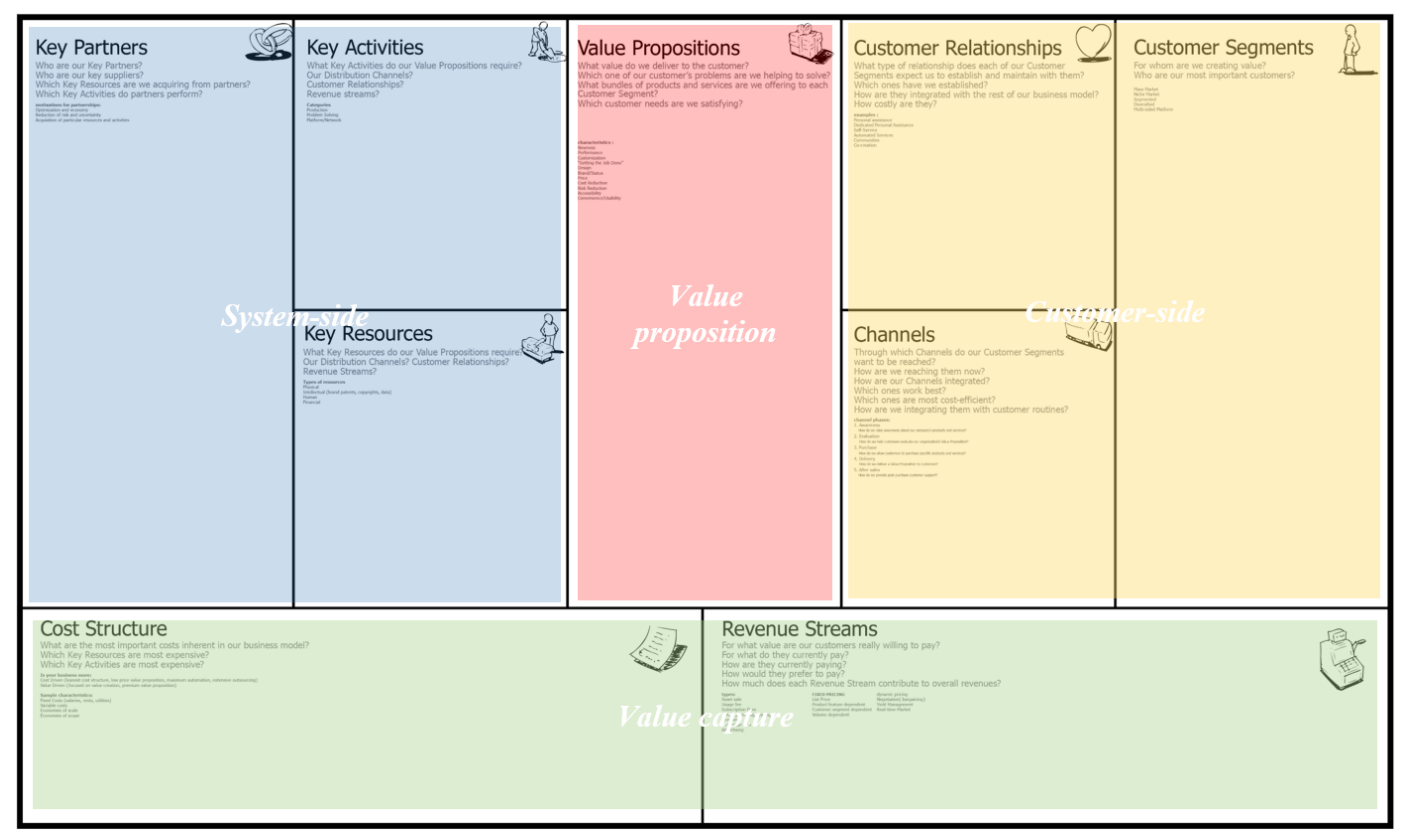

Fig. 1: Four main fields of business model canvas; Source: Authors

Today, whenever the word innovation is heard, it is directly associated with products or services research and development, or the creation of new ones; which is only part of a business model: The value proposition. However, "business model innovation is a wonderful thing. At its simplest, it demands neither new technologies nor the creation of brand-new markets" (Girotta and Netessine, 2014). In fact, innovation in products or services, without innovating in the other parts of the business model, is not enough to drive a competitive advantage (Zott et al., 2011).

Innovation in business models refers to changes on these decisions: What you will offer, when will decisions be made, by whom and why (Girotta and Netessine, 2014). Innovation in business encompasses the redesign of any part that determine the operation of the company with a clear objective: To gain a competitive advantage over the competition. If a business model is the stories that tell how a company works, the innovation of the business model is to rewrite any of those stories.

The business model canvas divides any business model in nine basic components and they are placed forming a template so that the visualization of the relation between the different parts of the business is simple, "that helps the user to map, discuss, design and invent new business models" (Ching and Fauvel, 2013). However, in literature, many authors, such as Ballon (2007) or King (2010), go further and simplify the business model canvas by grouping the nine blocks into four (Fig. 1). This new structure of the business model lies in the fact that the relationships and dependencies between some of the nine blocks are close enough to form a single block. These four elements are: Customer- side, value proposition, system-side and value capture. The greatest limitation of the canvas business model is the exclusion of external forces or agents, that is, the exclusion of the strategy. Therefore, since it is not intended to study the market strategy of companies and only their internal business structure, the canvas business model is considered the best tool for the study.

\section{Spanish Electricity Grid Legislation}

The legislation of the Spanish electricity grid constitutes an electric power system composed of six agents: electricity producers, distributors and retailers, system operator, market operator and industry supervisor. The latter three are public designation bodies. In Spain, the electric power industry is mostly integrated -approximately $80 \%$ - by five major power companies: Endesa, Iberdrola, Naturgy, EDP and Viesgo; the first three reach $65 \%$ of the market share (CES, 2018).

The current literature study (Ritcher, 2013; 2012; Engelken et al., 2015; de Roca 2018; 2019; Bughin et al., 2010; Loebbecke and Picot, 2015; Cotteleer and Sniderman, 2017; Lee et al., 2014) of the opportunities presented by the electricity sector has collected and identified certain effects derived from renewable energies and big data, as it is depicted on Table 2 .

\section{Methodology}

To achieve a minimum of validity, the following minimum requirements were established: Data was data was collected from the three out of the top five electricity companies by power capacity, power annually generation, clients and sales in Spain. 
Table 1: Companies interviewed and position of innovation experts

\begin{tabular}{llll}
\hline & Company 1 & Company 2 & Company 3 \\
\hline Activities & Generation, distribution and retail & Generation, distribution and retail & Generation, distribution and retail \\
Expert position & Head of Idea Hub & Member of innovation start-up program & InnovaHub Leader \\
$\mathrm{N}^{\circ}$ employees & $>6.000$ & $>6.000$ & $>6.000$ \\
$\mathrm{~N}^{\circ}$ customers & $3-12 \mathrm{~m}$ & $3-12 \mathrm{~m}$ & $3-12 \mathrm{~m}$ \\
Generation capacity & $>15 \mathrm{~m} \mathrm{GW}$ & $>15 \mathrm{~m} \mathrm{GW}$ & $>15 \mathrm{~m} \mathrm{GW}$ \\
EBITDA & $2-5 \mathrm{bn}$ euros & $2-5 \mathrm{bn}$ euros & $2-5 \mathrm{bn}$ euros \\
\hline
\end{tabular}

These would represent $50 \%$ of the electric power sector in terms of market share considering companies had the same market relevance. As an exploratory study, questions are open-ended and the structure of the interview should be flexible to small order changes, the omission of certain questions or inclusion of others as it is conducted. Therefore, it is a semi-structured interview (Saunders et al., 2009). The total number of companies interviewed is three, all having generation, distribution and retail of electricity activities. The participants interviewed are heads of innovation departments of their respective companies (Table 1), in literature called interviews with experts. The interviews were conducted during the second quarter of 2019, in person and lasted on average one hour.

\section{Results and Discussion}

The initial hypotheses on the effects of renewable energies and big data on the biggest power companies' business models are discussed hereunder with the results obtained on interviews. This comparison is divided according to the four elements of the business model canvas: Customer-side, value proposition, system-side and value capture (Table 2).

One of the recurrent results in reviewing renewable energy literature is that renewable energies literature will not have an excessively significant impact on business models due to the fact that renewable generation is interchangeable with traditional generation (Ritcher, 2013). The energy generated is exactly the same. However, the research shows the following.

As for the customer-side, interviews reveal how the renewable origin of energy is not only a customer's need (Ritcher, 2013) but has truly become a firm condition for customers. In addition, customers demand greater simplicity when it comes to knowing whether the energy they consume is renewable in origin or not. On the other hand, renewable energy has promoted a new separation in customer groups. Large companies that have added renewable energy consumption as one of their lines within their sustainability plans, even though they are already large energy consumers, are sold the energy differently, with Power Purchase Agreements (PPA). The interviews confirm that renewable energy has become the focus of companies' marketing strategy, as well as unveiling a new and better, more lasting relationship based on the services of selfconsumption consultancy.

Products for self-consumption and consulting services have not yet broken into the sector due to a lack of legislation. However, innovation leaders say that the recent change in regulation on self-consumption will drive the development of self-consumption. This is going to generate new business models. The value proposition has also undergone an incremental change by adding the renewable origin to energy.

Certification of the renewable origin of energy is also generating new business opportunities. Whether through guarantees of origin, green certificates or certification systems used in the future, trading companies can purchase energy with a differential value even without having generating activities. The interviews confirm the assumptions raised about renewable brand value and the inevitable investment in renewable energy infrastructure. Power companies are carrying out demanding plans to increase their renewable generation capacity. As a result of the increase in renewable generation plants, companies need a greater number of renewable energy specialists to be able to operate new parks. Interviews also reveal a clear difference from initial hypotheses. The literature review concluded that the cooperation of generators with supply companies or other generators would be crucial (Ritcher, 2013). However, innovation managers explain how small companies need partnerships with major suppliers and banks, while major companies can secure financing to build a plant and operate that power plant by themselves. Finally, it is discovered that renewable energies require prediction activities because of the low generation flexibility they boast.

With respect to value capture, the high investment in renewable infrastructures that clean energy represents (AEER, 2017) is confirmed, as well as the reduction in risk derived from the elimination of fossil fuels as a resource.

As far as the effects of big data are concerned, the data demonstrates how process optimization and efficiency improvement are the main applications within the business model. 
Table 2: Initial hypotheses without empirical support (in red), results not formulated in the hypothesis (in green) and empirically corroborated hypotheses (in black) on the effects of renewable energies and big data on the business models of Spanish biggest energy power companies ${ }^{\text {(in superscript the appropriate references and interviews where they have appeared) }}$

\begin{tabular}{|c|c|c|c|c|}
\hline & Customer-side & Value proposition & System-side & Value capture \\
\hline $\begin{array}{l}\text { Renewable } \\
\text { energy }\end{array}$ & $\begin{array}{l}\text { - } \text { renewable necessity }^{(9)} \\
\text { requirement }^{(\mathrm{ABC})} \\
\text { - } \mathrm{PPA}^{(\mathrm{B})} \\
\text { - } \text { marketing strategy }^{(9,11,13)(\mathrm{AB})} \\
\text { - } \text { need of simplicity }^{(\mathrm{AC})} \\
\text { - } \text { consulting services }^{(9)}, \\
\text { lasting relationship }^{(\mathrm{A})}\end{array}$ & $\begin{array}{l}\text { - renewable energy }(9,11,13)(\mathrm{ABC}) \\
\text { new products for self- } \\
\text { consumption }^{(9,11)}\end{array}$ & $\begin{array}{l}\text { - } \text { renewable image }^{(9,10,11,13)(\mathrm{ABC})} \\
\text { guarantees and certificates } \\
\text { of origin }(13)(\mathrm{AB}) \\
\text { - renewable infrastructure } \\
\text { - } \text { human resources }^{(\mathrm{ABC})} \\
\text { requires prediction activities }(\mathrm{ABC}) \\
\text { cooperation with generators }^{(9)}\end{array}$ & 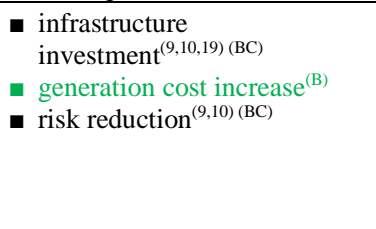 \\
\hline
\end{tabular}

New techniques for analyzing large amounts of data allow companies to have a deeper knowledge of customers. This innovation source is materialized in personalized rates for each consumer within each customer segment satisfying the simplicity demanded by customers. This use of big data is not particular to the electricity sector; indeed, it is being implemented in all business models of any industry. In addition, big data encourages the establishment of digital channels as a communication channel since all information obtained from customers is processed. This knowledge of the customer along with digital channels and big data, which represent an accessible and direct communication channel, culminates in a better relationship with the customer by being able to offer a greater amount information in a simpler way, such as their consumption. Moreover, greater knowledge of the customer is used in specific customer retention activities. Big data makes it possible to anticipate customer behavior and offer them a personalized value proposition.

Big data also promotes the development of new digital products, which represent a virtually inexhaustible source of data about customers or the network, in its application to smart grids.

Regarding the system-side, the initial assumptions indicated that big data represents an increasingly fundamental resource for companies: Information (Bughin et al., 2010). The analysis of large amounts of data is used as support in decision-making and as a tool for process optimization. Interviews reveal that power companies implement big data both in demand prediction activities such as operating activities and predictive maintenance. Big data is, in short, a source of efficiency improvement and process optimization.

In terms of value capture, the digitization of assets and activities is a capital investment. Predicting energy generation and demand makes it easier for companies to predict market behavior and thus better adapt their generation to market needs. As a result, companies can reduce their operational risk, resulting in lower costs. Besides, predictive maintenance reduces business model costs.

\section{Radical and Incremental Changes}

Electricity supply is a business that serves every group in society, from citizens and households, businesses and industry to special supply institutions. Renewable energy and, in particular, the consumer renewable energy requirement has enabled new segmentation of customers as they require guaranteed energy of renewable origin or not. This incremental change in customer groups is increased by data analysis techniques, allowing for more customized rates based on different customer groups.

As for value proposition, while electricity undergoes an incremental change, there are two radical changes when two new product groups appear: Those for self-sufficiency and self-consumption and new digital products.

Regarding channels, big data drives the use of the Internet, social networks and other digital channels as a means of communication with customers mainly because these digital channels represent a source of information for the company. Alongside this, other incremental changes are due to the fact that the analysis of large amounts of data allows companies to simplify the information provided to customers, as well as deepen the knowledge of them and improve customer retention activities. On the other hand, renewable energies have become the central theme of advertising activities. Similarly, a new activity has arisen for customer relations: Consulting services for self-sufficiency.

Companies' revenue streams have been slightly affected by renewable energy and big data. Customer segments that require renewable energy are willing to pay a little more for the energy supplied to them. Also, big data allows to optimize the purchase and sale of energy in the market.

In terms of key resources, companies' human resources have been increased as they need renewable energy experts and expert big data analysts. In terms of 
infrastructure, power plants are still needed, however, these are now renewable. In addition, a process of digitalization of infrastructures and assets is underway to optimize processes and improve efficiencies across all parts of the business. Generation physical resources such as fossil fuels have been gradually replaced by new natural resources, which cannot be controlled. Guarantees and certificates of origin take on a fundamental role in the business model by appearing as a new intangible resource necessary for the value proposition. Big data, on the other hand, enables companies to exploit the information resource with much higher performance than before. Finally, renewable brand value is a fundamental intangible resource, being a radical change in the model.

Regarding the key activities of the companies no radical changes are perceived, but that the activities of operation, maintenance and $\mathrm{R}+\mathrm{D}+\mathrm{i}$ notice incremental changes. Renewable energies mean less controllability of operating activities, which is mitigated by the generation and demand prediction activities optimized by big data. Analyzing large amounts of data allows predictive maintenance of infrastructures and assets.

Among the main partners of the companies, the market operator and the single carrier acquire greater importance, due to the lower controllability of renewable generation and the consequent greater difficulty in matching the supply and demand of electricity in the system. Besides, two new partners appear: the large companies that agree to the power supply (PPA) and in the years to come the load aggregators.

Finally, with respect to the cost structure of the business model, the same items continue to exist, although they are increased or decreased by renewable energies and big data. Renewable energies mean a reduction in the costs of generation resources and an increase in operating costs and investment in renewable infrastructures. In terms of risk, although this is diminished by the independence of fossil fuels, it is also increased due to the meteorological dependence on renewable generation. Big data means a reduction in operating costs, maintenance costs and risk due to prediction, as well as an increase in investment in the digitalization of infrastructures and assets.

All these changes that renewable energies and big data have generated in the business models and that have been described in the previous lines have been reflected in a business model canvas. In this way, Figure 2 shows the common business model of the companies interviewed. The effects that renewable energies and big data have had on the model have been added in green and blue colors, respectively. Radical changes have been indicated with completely new words and incremental changes have been indicated with arrows according to whether they have given greater or lesser importance to the parts of the model that already existed previously.

\section{Similarities and Differences}

Renewable energies, like big data, have allowed for greater segmentation of customers. Moreover, a new client has emerged due to renewable energies: PPAs; as well as in the future big data will result in a new customer: Aggregators.

Both renewable energy and big data have given rise to two new types of products: Products for selfconsumption and digital products, respectively. It should be noted that while the renewable origin does imply an incremental improvement of electricity, big data does not entail any improvement of the product offered.

As for the channels, it should be noted that none of these sources of innovation changes or modifies the transport of electricity, which continues to be through single carrier and distribution companies by transformation stations, transport lines, distribution lines and auxiliary centers.

Both achieve a better relationship with the customer, who is given more information in a simpler way, either about their consumption or on issues related to selfsufficiency.

On the other hand, while renewable energies can be used to arouse greater interest in customers and attract them, information analysis techniques can be used to gain a deeper understanding of their behavior. In other words, they're complementary.

In terms of revenue streams, both renewable energy and big data materialize in higher revenues due to better retail and better sales on the market, respectively.

Several similarities can be found with regard to the resources required for the business model. Human resources demanded by both renewable energy and big data are more specialized profiles. Similarly, within the necessary infrastructures, renewable assets and digitization are becoming increasingly relevant within the model. In terms of generation resources, there is a replacement of fossil fuels with information. Renewable plants do not require oil, natural gas or coal. However, the higher the percentage of renewable energy the more information is needed as a resource to anticipate electricity generation and demand. Ultimately, renewable energies have created an increasingly differentiating intangible resource: The renewable brand value. In a hypothetical renewable future where most companies are renewable, will the level of digitalization be the value of a differentiating brand?

The effects of renewable energy and big data in operation are complementary again. While renewable energy reduces generation controllability, data-intensive analysis techniques fill the need for high levels of controllability by predicting energy generation and consumption. Both renewable energy and big data are part of the innovation lines of power companies and new projects are developed based on them. 


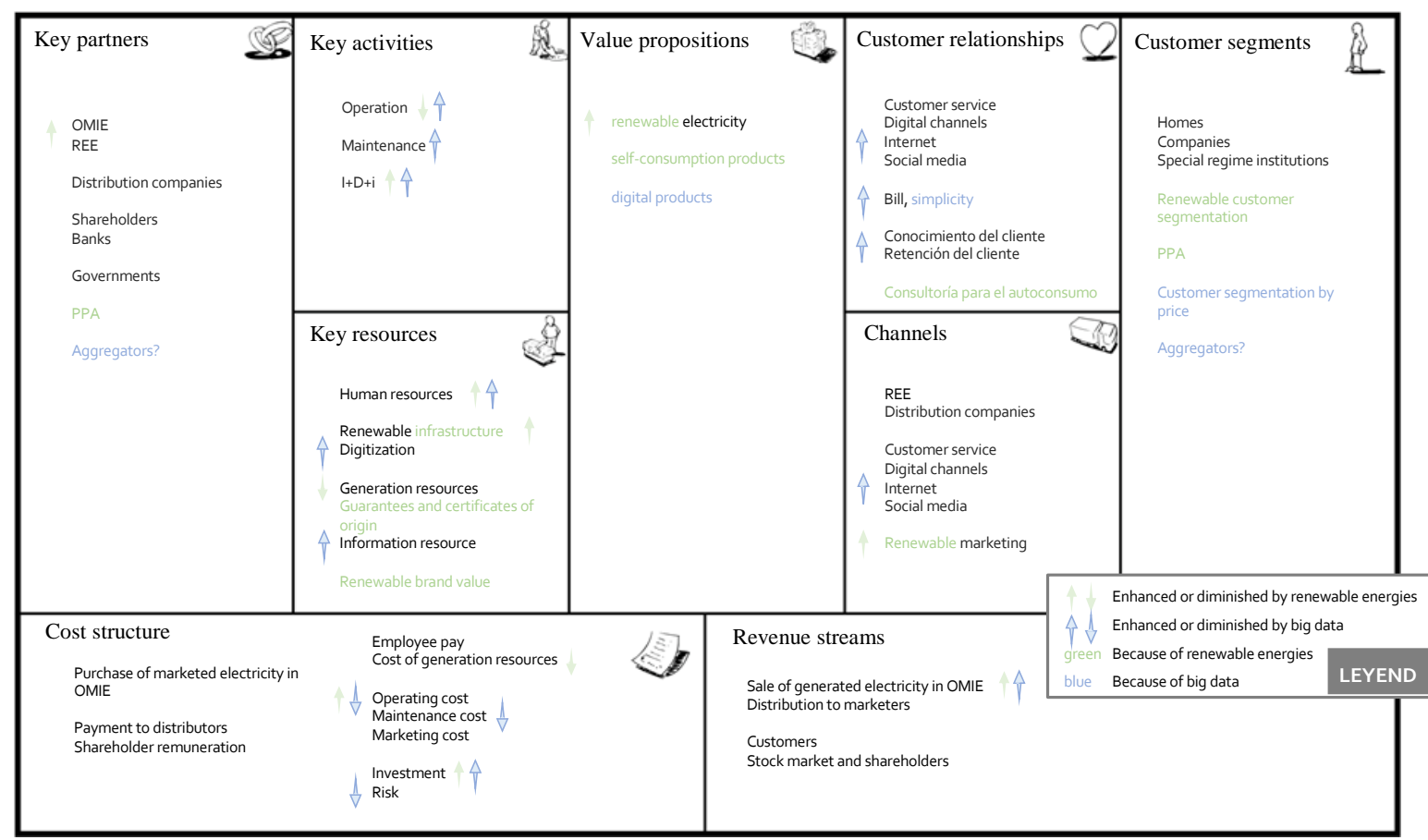

Fig. 2: Business model canvas on the effects of renewable energies (in green) and big data (in blue) on the business models of electricity companies in Spain; Source: Authors

In terms of cost, the implementation of both sources of innovation represents an extraordinary capital investment.

In general, it should be appreciated that the sector, as well as companies, are not radically affected by these sources of innovation. Value proposition, physical distribution channels of energy, revenue structure and cost structure (the latter two in terms of the purchase and sale of electricity on the market, distribution and shareholders) are virtually unaffected renewable energy and big data. In addition, the customers to whom energy is supplied are the same, the entire society as a whole and the activities of the companies are also the same. In short, the essential functioning of the electricity sector remains the same, especially the functioning of the market and the transport and distribution of energy. Simply change or improve the processes to perform the different activities, either with new resources or to seek for different interactions with customers.

\section{Conclusion}

Exuberant demand for renewable energy by customers, among other things, has meant the investment of electricity companies in renewable infrastructure to increase their renewable generation capacity. Certification methods have also been developed to guarantee consumers the renewable origin of the energy supplied to them.

As for big data, this has been discovered as a fundamental element in process optimization that facilitates the prediction of the generation and demand of electricity and predictive maintenance, with its corresponding effect on the company's cost structure. Similarly, new data analysis techniques have enabled the particularization of products as customized tariffs.

Two main findings of the investigation are as follows. Firstly, renewable energies together with big data has meant replacing traditional generation resources with information resources. The higher the percentage of renewable energy the less fossil fuels will be needed, among others and the more essential the resource of information will be to predict electricity generation and consumption. Secondly, it has been proven that both sources of innovation do not yet imply a change in the functioning of the electricity sector, especially in the market, transport and distribution of electrical energy.

In addition, renewable energies and big data are the origins of new business models and new markets beyond the traditional model of electricity supply. Renewable sources are the core of the self-supply market that houses products such as photovoltaic panels for households and associated consulting services. On the other hand, big data facilitates the addition of digital products as part of business models, as these are a key source of information.

\section{Future Guidelines}

Thanks to this study, the most relevant effects of renewable energies and Big Data on the business models of companies in the electricity sector have been determined. Following the natural evolution of the research, the future lines of research are proposed below: 
- It is proposed to consider the degree of maturity of the technologies and the business models in these five pillars: technology, market, commercial strategy, regulation and social acceptance

- To identify and analyze the innovation methodology currently used by companies in the electricity sector in Spain

- $\quad$ To identify and study in depth all the opportunities and barriers to which renewable energies and big data give rise to. In particular, to study the emergence of countless retailers that base their business models mainly on renewable energies to sell clean energy and big data for the management of this energy. Thus achieving an attractive model for the consumer and profitable for the company, respectively

- Finally, to draw up a proposal of recommendations and political measures to be implemented in pursuit of optimum national development of the electricity sector or even to propose, after a study, a better model of the electricity sector and market than the current one

\section{Ethics}

We ensure that the content present in this article are the original work of an authors and contains unpublished material. The article submit for the publication is carefully read by author and approve for publication. There were no conflicts of interest in this work. The author worked objectively and independently in preparing this paper.

\section{References}

AEER, 2017. Estudio del impacto macroeconómico de las energías renovables en España. Asociación de Empresas de Energías Renovables - APPA Renovables.

Ballon, P., 2007. Business modelling revisited: The configuration of control and value. Info, 9: 6-19. DOI: $10.1108 / 14636690710816417$

Bughin, J., M. Chui and J. Manyika, 2010. Clouds, big data and smart assets: Ten tech-enabled business trends to watch. McKinsey Quarterly, 56: 75-86.

CES, 2018. Informe 04/2017 El sector eléctrico en España. Consejo Económico y Social, Madrid.

Ching, H.Y. and C. Fauvel, 2013. Criticisms, variations and experiences with business model canvas. Eur. J. Agric. Forestry Res., 1: 26-37.

Cotteleer, M. and B. Sniderman, 2017. Forces of change: Industry 4.0. Deloitte Services LP, Center for Integrated Research.

Darmani, A., N. Arvidsson, A. Hidalgo and J. Albors, 2014. What drives the developement of renewable energy technologies? Toward a typology for the systemic drivers. Renewable Sustainable Energy Rev., 38: 834-847. DOI: 10.1016/j.rser.2014.07.023 de Roca, A., 2018. El modelo de negocio de las compañías eléctricas: Nuevos actores, nuevos roles, nuevas reglas.

de Roca, A., 2019. Magnus commodities, Garantías de Origen $(\mathrm{GdO})$.

Engelken, M., B. Römer, M. Drescher and I.M. Welpe, 2015. Comparing drivers, barriers and opportunities of business models for renewable energies: A review. Renewable Sustainable Energy Rev., 60: 795-809. DOI: 10.1016/j.rser.2015.12.163

Girotra, K. and S. Netessine, 2011. How to build risk into your business model. Harvard Bus. Rev., 89: 100-105.

Girotta, K. and S. Netessine, 2014. Four paths to business model innovation. Harvard Bus. Rev., 92: 96-103. DOI: $10.2139 /$ ssrn.2289291

King, R., 2010. Advanced business model canvas.

Lee, J., H.A. Kao and S. Yang, 2014. Service innovation and smart analytics for Industry 4.0 and big data environment. Proc. CIRP, 16: 3-8. DOI: $10.1016 /$ j.procir.2014.02.001

Loebbecke, C. and A. Picot, 2015. Reflections on societal and business model transformation arising from digitization and big data analytics. J. Strategic Inform. Syst., 24: 149-157. DOI: $10.1016 /$ j.jsis.2015.08.002

Magretta, J., 2002. Why business model matters. Harvard Bus. Rev., 80: 86-92.

Ritcher, M., 2012. Utilities' business models for renewable energy: A review. Renewable Sustainable Energy Rev., 16: 2483-2493. DOI: $10.1016 /$ j.rser.2012.01.072

Ritcher, M., 2013. Business model innovation for sustainable energy: German utilities and renewable energy. Energy Policy, 62: 1226-1237.

DOI: 10.1016/j.enpol.2013.05.038

Saunders, M., P. Lewis and A. Thornhill, 2009. Research Methods for Business Students. 5th Edn., Pearson Education Limited, Harlow, Essex, ISBN-10: 0273716867, pp: 614.

Winston, A., 2014. Two forces moving business closer to climate action. Harvard Bus. Rev.

Zott, C., R. Amit and L. Massa, 2011. The business model: Recent developments and future research. J. Manage., 37: 1019-1042. DOI: $10.1177 / 0149206311406265$ 